\title{
Transcellular transport of West Nile virus-like particles across human endothelial cells depends on residues 156 and 159 of envelope protein
}

\author{
Rie Hasebe*1,2, Tadaki Suzuki1, Yoshinori Makino 1,4, Manabu Igarashi³, Satoko Yamanouchi', Akihiko Maeda2, \\ Motohiro Horiuchi², Hirofumi Sawa1,4 and Takashi Kimura'
}

\begin{abstract}
Background: West Nile virus (WNV) causes viremia after invasion to the hosts by mosquito bite. Endothelial cells could play an important role in WNV spread from the blood stream into the central nervous system and peripheral tissues. Here, we analyzed the capacity of virus-like particles (VLPs) of the highly virulent NY99 6-LP strain (6-LP VLPs) and the low virulence Eg101 strain (Eg VLPs) to cross cultured human endothelial cells.

Results: 6-LP VLPs were transported from the apical to basolateral side of endothelial cells, whereas Eg VLPs were hardly transported. The localization of tight junction marker ZO-1 and the integrity of tight junctions were not impaired during the transport of 6-LP VLPS. The transport of 6-LP VLPs was inhibited by treatment with filipin, which prevents the formation of cholesterol-dependent membrane rafts, suggesting the involvement of raft-associated membrane transport. To determine the amino acid residues responsible for the transport of VLPS, we produced mutant VLPs, in which residues of E protein were exchanged between the 6-LP and Eg strains. Double amino acid substitution of the residues 156 and 159 greatly impaired the transport of VLPS.

Conclusion: Our results suggest that a transcellular pathway is associated with 6-LP VLPs transport. We also showed that the combination of the residues 156 and 159 plays an important role in the transport of VLPs across endothelial cells.
\end{abstract}

\section{Background}

West Nile virus (WNV), a mosquito-borne singlestranded RNA virus, had been known to cause endemic febrile disease in Africa, the Middle East, Europe and Asia [1-4]. Since the concurrent outbreaks of encephalitis among humans, horses and birds in New York in 1999 [57], WNV has spread rapidly across North America [8]. WNV has considerable public health impact because of large annual epidemics of human neuroinvasive disease [9]. WNV proliferates in birds and is transmitted to humans, horses and other animals by mosquitoes. After invading the hosts, WNV seems to proliferate in lymphoid tissue and causes viremia [10]. WNV then penetrates the blood brain barrier (BBB) and causes encephalitis with neuronal cell death. Neurons are the

\footnotetext{
* Correspondence: r-hasebe@vetmed.hokudai.ac.jp

1 Department of Molecular Pathobiology, Hokkaido University Research Center for Zoonosis Control, Kita 20, Nishi 10, Kita-ku, Sapporo 001-0020, Japan

Full list of author information is available at the end of the article
}

main target of the virus in the central nervous system (CNS), since viral antigens are mainly detected in these cells [11].

In addition to the neuronal disease, WNV-associated inflammation outside the CNS can occur in humans. Khouzam [12] reported the case of a patient who had diffuse myocardial damage secondary to WNV infection. Rhabdomyolysis was reported in a patient with WNV encephalitis [13]. Armah et al. [14] reported systemic distribution of WNV infection in 6 human cases in which viral antigens were detected in CNS, kidney, lungs, pancreas, thyroid, intestine, stomach, esophagus, bile duct, skin, prostate and testis. These studies suggest that WNV can invade and proliferate in multiple tissues.

Shirato et al. [15] suggested that the difference in the neuroinvasiveness between the highly virulent NY99 strain and the non-lethal Eg $101(\mathrm{Eg})$ strain is associated with the viral replication in spleen. One of the reasons 
NY99 strain gains this virulent phenotype might be an enhancement of invasiveness to the peripheral tissues. Blood-borne pathogens must encounter endothelial cells of blood capillaries to invade the target organs. Verma et al. [16] demonstrated the mechanism by which WNV crosses endothelial cells using human brain microvascular endothelial (HBMVE) cell culture. Their data suggested that WNV crosses HBMVE cells via a transcellular pathway after viral replication in endothelial cells. However, the possibility that WNV crosses endothelial cells without viral replication cannot be excluded, since WNV infection of endothelial cells is rarely detected in human cases [17]. It is still unclear if a transcellular mechanism is also involved in viral invasion to endothelial cells of peripheral tissues.

In this study, we assessed the possibility that WNV has an ability to cross human endothelial cells. To eliminate the influence of viral replication in endothelial cells, we used virus-like particles (VLPs) which can infect susceptible cells without production of progeny virions. Our results suggest that VLPs of the NY99-6922 6-LP (6-LP) strain cross human umbilical vein endothelial cells (HUVEC) by a transcellular pathway. We also showed that the 6-LP VLPs were transported greater than VLPs of the low-virulence Eg strain, which depends on Ser 156 and Val 159 of E protein.

\section{Results}

\section{WNV 6-LP VLPs are transferred across human endothelial} cells

HUVEC were seeded on the membranes of transwells, which have $0.4 \mu \mathrm{m}$ pores. The presence of the tight junction with an increase of transendothelial electrical resistance (TEER; 66-77 $\Omega \mathrm{cm}^{2}$ ) was confirmed 3 days after seeding. Here we used VLPs previously reported by Scholle et al. [18]. VLPs can infect cells because of the presence of the structural proteins $(\mathrm{C}$, prM/M and $\mathrm{E}$ protein) that are present in infectious virions. VLPs contain replicon RNA, which encodes the WNV nonstructural proteins and the enhanced green fluorescent protein (eGFP), but lacks the sequence of structural proteins. After VLP infection of susceptible cells, replicon RNA is released and replicates in the cytoplasm accompanied by the expression of eGFP. However, progeny particles are not produced because of the lack of expression of structural proteins in VLP-infected cells.

To assess the possibility that HUVEC can transport VLPs, HUVEC were exposed to 6-LP VLPs or Eg VLPs at a multiplicity of infection (m.o.i.) of $2\left(4 \times 10^{4}\right.$ infectious unit/transwell). The number of VLPs transferred to the lower chambers was determined by infectious unit (IFU) assay at 0,8 and $24 \mathrm{~h}$ post infection (p.i.) (Fig. 1). 6-LP VLPs were detected at $8 \mathrm{~h}$ p.i. and increased approximately 2 -fold at $24 \mathrm{~h}$ p.i. On the other hand, few Eg VLPs

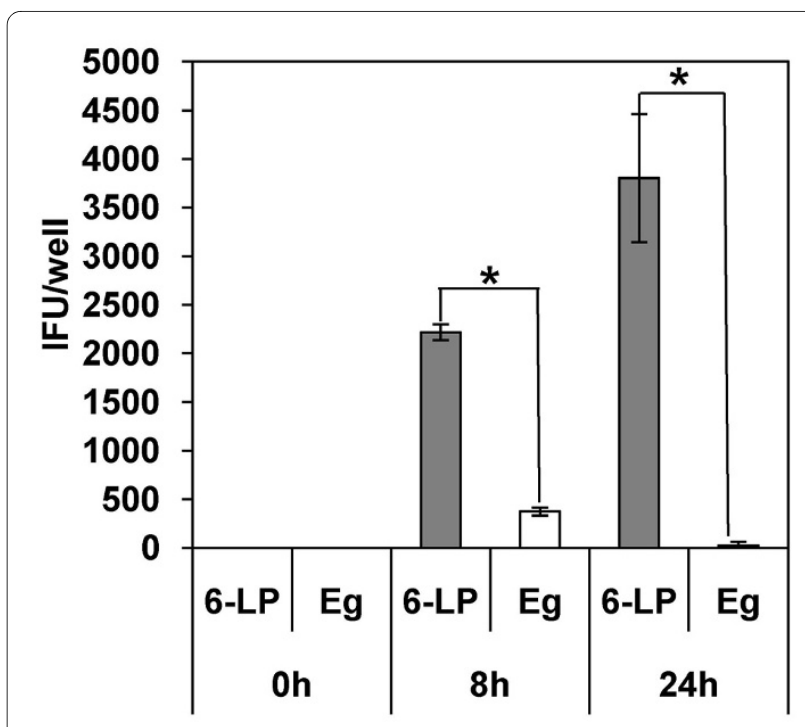

Figure 1 Transport of 6-LP and Eg VLPs across a monolayer of HUVEC. HUVEC were exposed to VLPs for 0,8 or $24 \mathrm{~h}$. The numbers of transferred VLPs were determined by IFU assay. Gray bars, 6-LP VLPS. White bars, Eg VLPs. The graphs show the mean of three determinations. The error bars show SD. The results are representative of 2 independent experiments. ${ }^{*} p<0.01$.

were detected at 8 and 24 h p.i. The amount of the transferred 6-LP VLPs was significantly higher than that of Eg VLPs at 8 and 24 h p.i. $(\mathrm{p}<0.01)$. These results suggested that 6-LP VLPs were transferred across HUVEC and that the transfer of Eg VLPs was much less efficient.

\section{6-LP VLPs were transported without altering the integrity of tight junction}

Verma et al. [16] suggested that WNV replicates in the HBMVE cells and that the progeny virus crosses the BBB via a transcellular pathway without impairing the integrity of tight junction. However, VLPs used in this study do not produce progeny virions. Thus, there is a possibility that 6-LP VLPs cross from the apical to the basolateral side by disrupting tight junction.

To assess this possibility, the distribution of a tight junction marker ZO-1 was analyzed by immunocytochemistry at $24 \mathrm{~h}$ p.i. (Fig. 2A). The localization of ZO1 was not visibly affected in 6-LP VLP-exposed HUVEC, when compared to the untreated control. We also measured the permeability of 70k Dextran (Dx) to check the integrity of the tight junction (Fig. 2B). The permeability of 70k Dx in VLP-exposed HUVEC was similar to that in untreated cells by this assay. It has been known that TNF$\alpha$ exposure induces changes in endothelial cell morphology and permeability [19]. Therefore, we treated the cells by TNF- $\alpha$ as a control. Treatment of HUVEC with TNF- $\alpha$ at $2 \mu \mathrm{g} / \mathrm{ml}$ greatly impaired the integrity of the tight junction ( $<<0.01$; Figs. 2A and 2B). 


\section{A}

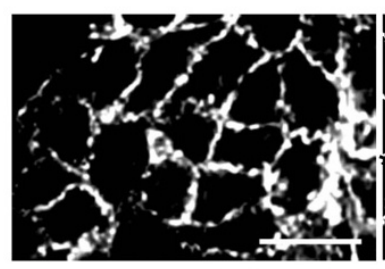

untreated

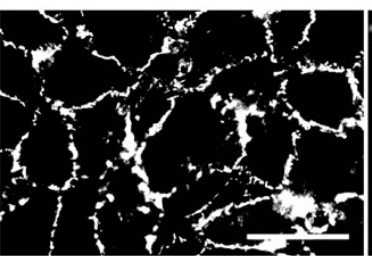

6-LP-exposed

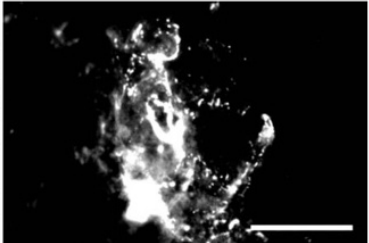

TNF- $\alpha$ treated

B

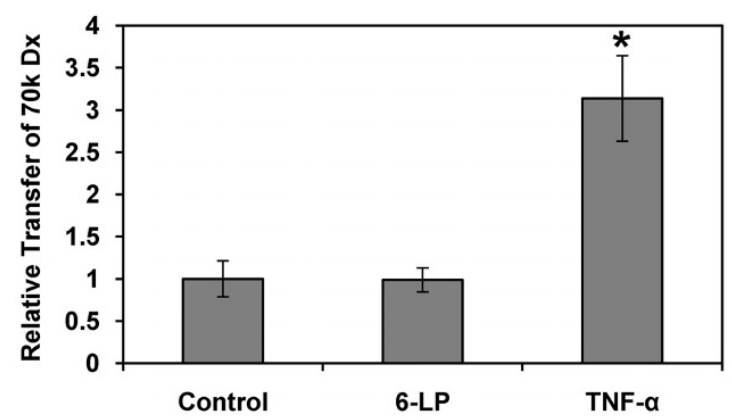

C

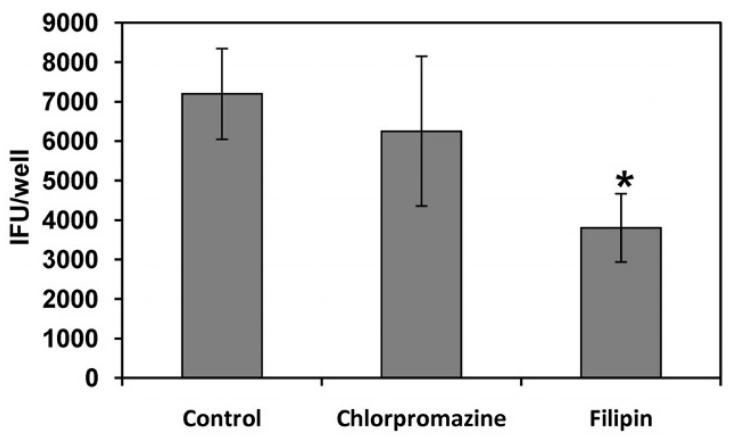

D

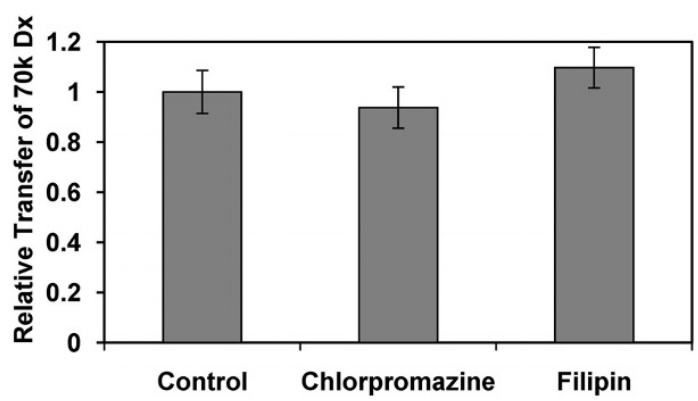

Figure 2 Transcellular transport of 6-LP VLPs in HUVEC. (A) Distribution of tight junction marker ZO-1 in HUVEC. HUVEC were exposed to 6-LPVLPS or treated with TNF-a for $24 \mathrm{~h}$. The cells were fixed and processed for immunofluorescence staining of ZO-1. Bars represent $50 \mu \mathrm{m}$. (B) Transfer of Dx70k into a monolayer of untreated, 6-LP VLP-exposed or TNF-a treated HUVEC. HUVEC were exposed to 6-LP VLPS or treated with TNF-a in the presence of FITC-labeled 70k Dx (FITC-70k Dx). After $24 \mathrm{~h}$, media were collected from lower chambers and the fluorescence of transferred 70k Dx was measured by a fluorescent plate reader. Relative transfer of FITC-70k Dx was calculated as described in METHODS. The graphs show the mean of three determinations. The error bars show SD. The results are representative of 2 independent experiments. ${ }^{*} p<0.01$. (C) Transport of 6-LP VLPs in HUVEC treated with endocytosis inhibitors. HUVEC were exposed to 6-LPVLPs in the presence or absence of $5 \mu \mathrm{g} / \mathrm{ml}$ of chlorpromazine or $1 \mu \mathrm{g} / \mathrm{ml}$ of filipin. The cells treated with $0.1 \%$ DMSO were used as control. After $24 \mathrm{~h}$, media at the lower chamber were collected and subjected to IFU assay. ${ }^{*} p<0.01$. (D) Transfer of FITC-70k Dx in HUVEC treated with endocytosis inhibitors. FITC-70k Dx was added to HUVEC with or without $5 \mu \mathrm{g} / \mathrm{ml}$ of chlorpromazine or $1 \mu \mathrm{g} / \mathrm{ml}$ of filipin. After $24 \mathrm{~h}$, medium was collected from the lower chambers and the fluorescence was measured. Relative transfer of FITC-70k Dx was calculated as described in METHODS. The graphs show the mean of three determinations. The error bars show SD. The results are representative of 2 independent experiments. 


\section{6-LP VLPs cross HUVEC via a transcellular pathway}

To assess the involvement of a transcellular pathway, we examined the effects of chlorpromazine and filipin on VLP transport. Chlorpromazine disrupts the recycling of AP-2 from endosomes and prevents the assembly of clathrin-coated pits on the plasma membrane [20]. Filipin is a sterol-binding agent and prevents the formation of cholesterol-dependent membrane rafts [21]. The optimal concentration of chlorpromazine and filipin was determined by the inhibition of the uptake of transferrin and cholera toxin subunit B, which are known as ligands for clathrin-and lipid-rafts-dependent endocytosis, respectively (data not shown). HUVEC were exposed to 6-LP VLPs in the presence or absence of the inhibitor. FITClabeled 70k Dx was also added to the transwells with 6-LP VLPs to evaluate the tight junction integrity. The transport of VLPs was inhibited by filipin $(\mathrm{p}<0.01)$, but was not significantly by chlorpromazine (Fig. $2 \mathrm{C}$ ). In contrast, the permeability of 70k Dx was not impaired by either chlorpromazine or filipin (Fig. 2D). These results suggested that lipid rafts are involved in VLPs transport.

\section{Transport of 6-LP VLPs depends on E protein}

It is known that $E$ protein interacts with viral receptors on the host cells [22-28] resulting in the induction of receptor mediated endocytosis $[25,29,30]$. To examine whether E protein is involved in the transport of VLPs, we generated chimeric VLPs using 6-LP and Eg VLPs. 6-LP CM Eg $\mathrm{E}$ VLPs have $\mathrm{C}$ and M/prM proteins derived from 6-LP strain and E protein from Eg strain. Eg CM 6-LP E VLPs have $C$ and $M / p r M$ protein from Eg strain and $E$ protein from 6-LP strain. HUVEC were exposed to wild type or chimeric VLPs and transported VLPs were detected by IFU assay at $24 \mathrm{~h} \mathrm{p.i} \mathrm{(Fig.} \mathrm{3).} \mathrm{The} \mathrm{transport} \mathrm{of} \mathrm{Eg} \mathrm{CM} \mathrm{6-LP}$ E VLPs was similar to that of wild type 6-LP VLPs and was significantly higher than those of 6-LP CM Eg E VLPs and wild type Eg VLPs $(\mathrm{p}<0.01)$. 6-LP CM Eg E VLPs were rarely transported across HUVEC as well as wild type Eg VLPs. These results suggest that the transport of VLPs across HUVEC is strongly affected by E protein.

\section{Multiple amino acid residues of $E$ protein influence the transport of 6-LP VLPs}

The E proteins of the 6-LP and Eg strain differ at 4 amino acid residues. To determine the residues that enhance the transport of 6-LP VLPs, we produced mutant VLPs (Table 1). 6-LP S156P VLPs and 6-LP V159I VLPs had significantly reduced transport compared to wild type 6LP VLPs $(\mathrm{p}<0.01)$ although the amount of transported VLPs was much higher than that of Eg VLPs $(\mathrm{p}<0.01$; Fig. 4A). As shown in Fig. 4B, Eg K93R VLPs and Eg T126I VLPs showed increased transport compared to wild type Eg VLPs $(\mathrm{p}<0.05)$. The transport of Eg I159V was significantly increased $(\mathrm{p}<0.01)$, although it was

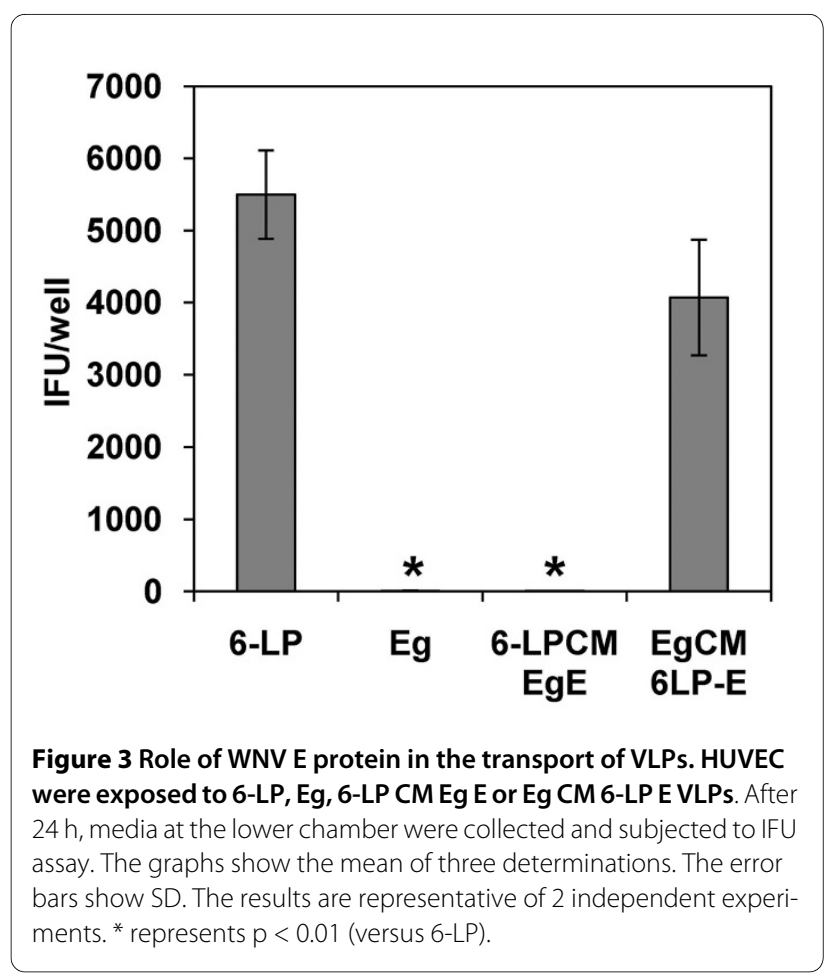

much lower than 6-LP VLPs. Previous studies reported that Ser 156 is involved in the N-linked glycosylation at 154, which is important for virulence and neuroinvasion [31-34]. Therefore, we expected that the transport of Eg P156 S would be increased. However, the transport of Eg P156 S VLPs was significantly lower than that of WT Eg VLPs $(p<0.01)$. These results suggest that multiple residues of $E$ protein can influence the transport of VLPs.

\section{The combination of Ser 156 and Val 159 is important for the} transport of 6-LP VLPs

From the result of Fig 4B, the transport of Eg P156 S did not increase. This finding suggests the possibility that the combination of amino acids at the position of 156 and 159 might affect the transport of VLPs. To assess this hypothesis, we generated double mutants, 6-LP S156P V159I and Eg P156 S I159V (Table 1). As shown in Fig. 5, the transport of 6-LP S156P V159I was greatly reduced (p $<0.01$; versus 6 -LP VLPs) to the level of wild type Eg VLPs. The transport of Eg P156 S I159V was greatly increased ( $p<0.01$; versus Eg VLPs) to the level of wild type 6-LP VLPs. These results suggest that the combination of Ser 156 and Val 159 is important for the transport of 6-LP VLPs across HUVEC.

Combination of amino acid sequence at 156 and 159 does not affect the $\mathrm{N}$-linked glycosylation of $\mathrm{E}$ protein

From the results of Figs. 4 and 5, we speculated that the combination of amino acid sequence at 156 and 159 might affect N-linked glycosylation at the position 154 
Table 1: Single and double mutant VLPs

\begin{tabular}{lccc}
\hline Name & Wild type & Position1 & Substitution2 \\
\hline 6-LP R93K & & & RTK \\
6-LP I126T & $6-$-LP & 93 & ITT \\
6-LP S156P & $6-$ LP & 126 & STP \\
6-LP V159I & $6-$-LP & 156 & VTI \\
Eg K93R & $6-$ LP & 159 & KTR \\
Eg T126I & Eg & 93 & TTI \\
Eg P156S & Eg & 126 & PTS \\
Eg I159V & Eg & 156 & 159 \\
6-LP S156P V159I & Eg & 156,159 & ITV \\
Eg P156 S I159V & $6-L P$ & 156,159 & STP, VTI \\
\hline
\end{tabular}

${ }^{1}$ Amino acid position of $\mathrm{E}$ protein.

${ }^{2}$ Amino acid substitution from wild type to mutant.

resulting in unglycosylation of E protein of Eg P156 S. To assess this possibility, we analyzed the glycosylation of $\mathrm{E}$ protein in 6-LP VLPs, Eg VLPs, 6-LP S156P, Eg P156 S, 6LP V159I, Eg I159V, 6-LP S156P V159I and Eg P156 S I159V. Western blotting of $E$ protein showed the band of wild type 6-LP strain was higher than that of Eg strain (Fig. 6. lanes 2 and 3) because of glycosylation. E protein

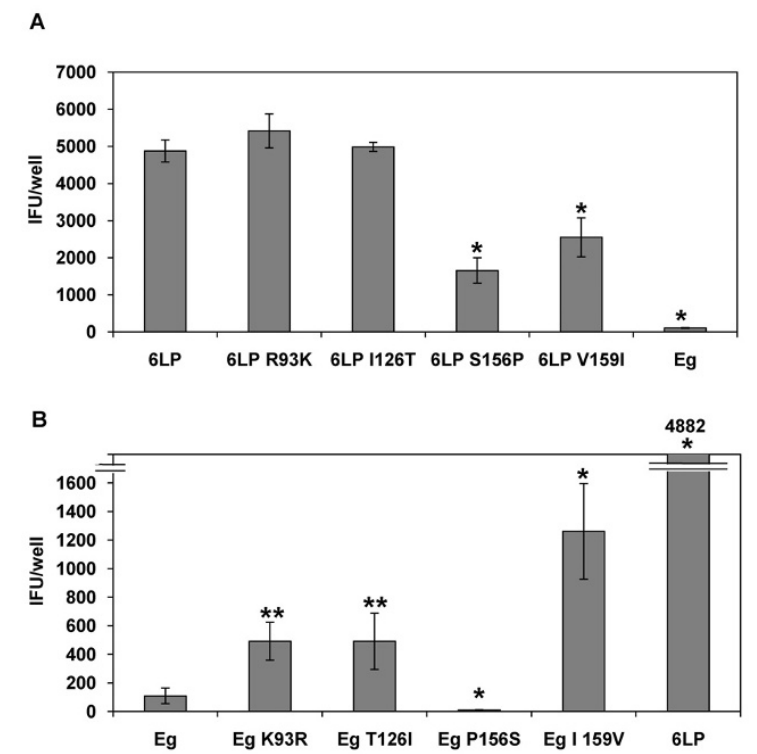

Figure 4 Effect of single amino acid substitutions in E protein on the transport of VLPs. HUVEC were exposed to mutant VLPS. After 24 $h$, media at the lower chamber were collected and subjected to IFU assay. (A) Transport of mutant 6-LP VLPs. *represents $p<0.01$ (versus 6LP). (B) Transport of mutant Eg VLPs. * and ${ }^{* *}$ represent $p<0.01$ and $p$ $<0.05$, respectively (versus $\mathrm{Eg}$ ). The graphs show the mean of three determinations. The error bars show SD. The results are representative of 2 independent experiments. of 6-LP S156P, Eg I159V and 6-LP S156P V159I was unglycosylated (Fig. 6. lanes 4, 7 and 8), whereas E protein of 6-LP V159I and Eg P156 S I159V was glycosylated (Fig. 6. lanes 6 and 9). Interestingly, E protein of Eg P156 S was also glycosylated (Fig. 6. lane 5). These results suggest that the combination of the residues 156 and 159 does not affect the N-linked glycosylation and that glycosylation of $\mathrm{E}$ protein is not the determinant of the transport of VLPs.

\section{Discussion}

WNV NY strains have a highly virulent phenotype compared to the Eg strain which was isolated in Africa. Their

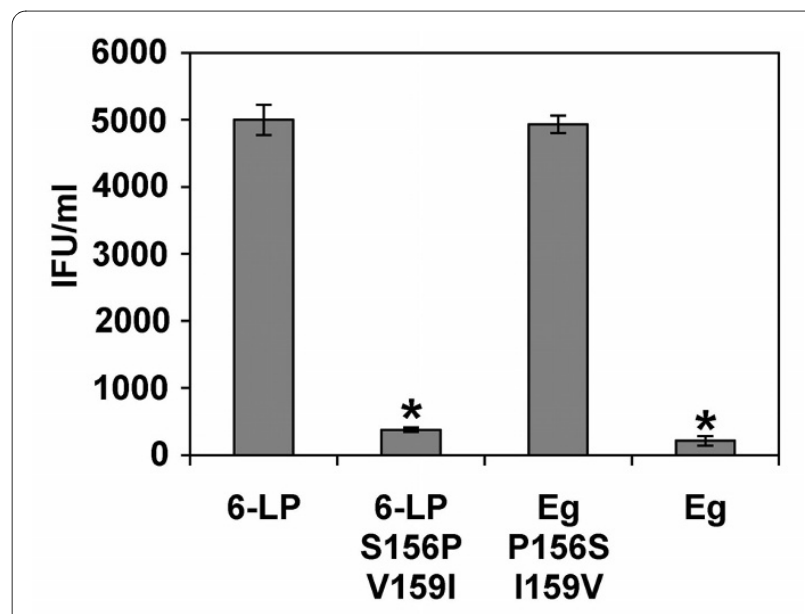

Figure 5 Effect of double amino acid substitutions of $E$ protein on the transport of VLPs. HUVEC were exposed to 6-LP, 6-LP S156P V159l, Eg P156 S 1159 V or Eg VLPs. After 24 h, media at the lower chamber were collected and subjected to IFU assay. ${ }^{*} p<0.01$ (versus 6-LP). The graphs show the mean of three determinations. The error bars show SD. The results are representative of 2 independent experiments. 


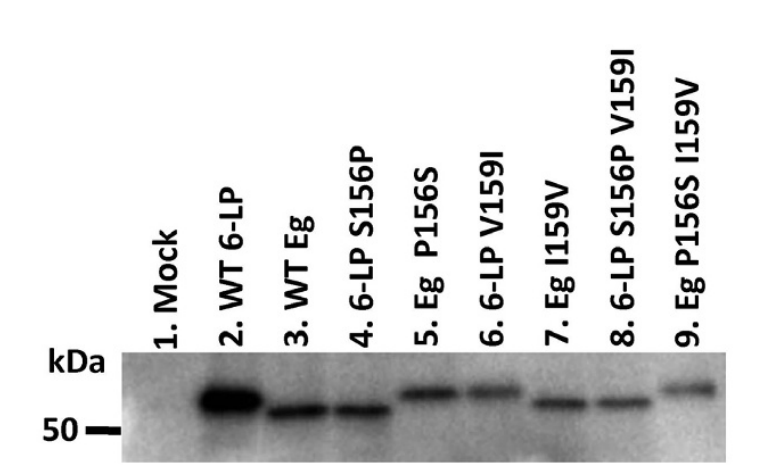

Figure 6 Glycosylation of E protein in wild type and mutant VLPs. 293T cells were cotransfected with replicon RNA and plasmids encoding structural genes or empty vector for mock control. The supernatants were collected and subjected to Western blotting with anti-WNV E protein monoclonal antibody.

enhanced replication in peripheral tissues may lead to long-lasting viremia resulting in increasing incidence of viral invasion to CNS. The interaction of the virus with endothelial cells of blood capillaries could be involved in WNV invasion to target organs. In this study, we assessed the transport of WNV NY99 6-LP strain and Eg strain across human endothelial cells. Our data demonstrate that VLPs of the 6-LP strain were transported across human endothelial cells more than VLPs of the Eg strain.

Microbial invasion across endothelial cells can occur through transcellular pathway mediated by vesicles, paracellular entry after disruption of the tight junctions, or "Trojan horse" mechanism by transport within circulating phagocytic cells $[35,36]$. Our data indicate that 6-LP VLPs are transported by a transcellular pathway, because the transport of VLPs was inhibited by the treatment with filipin, a modifier of lipid raft-associated membrane transport. Clathrin-dependent pathways seem to be less important because the treatment with chlorpromazine had no significant effect on the transport of VLPs. Paracellular entry is unlikely to be involved in transport of VLPs because the structure of ZO-1 and the permeability of Dx 70k were not altered during VLP transport.

Our data partially support the results by Verma et al. [16] which suggested that WNV crosses HBMVE cells without altering the integrity of tight junction. The authors concluded that WNV replicates in endothelial cells and the progeny viruses are transported from the apical to basolateral side. However, our data suggest that WNV can be transported across endothelial cells without viral replication. Cell type difference could be the most reasonable explanation, because several studies showed that there are differences between HBMVE cells and HUVEC in the production of growth factors, immunoregulatory factors and adhesion molecules [37-39]. HBMVE cells and HUVEC differentially respond to cytokine treatment resulting in the different cytokine production and leukocyte recruitment $[40,41]$. Particularly, modulation of adhesion molecules can affect endocytosis [37]. Therefore, our data seem to reflect events that can occur in peripheral tissues having tight junction such as heart and muscles rather than in CNS.

In WNV-infected mice, viral replication in peripheral tissues results in the inflammatory cytokine production such as TNF- $\alpha$, IL- 6 and macrophage migration inhibitory factor [42-45]. Although the role of these cytokines in infection still remains controversial, vascular permeability can be affected by the presence of these cytokines [45]. One of the mechanisms for the impairment of vascular permeability by these cytokines is disruption of tight junctions of endothelial cells [46]. Promotion of vesicular transport of endothelial cells, including pinocytosis and transcytosis, is also affected by these cytokines [47]. Paracellular invasion by disruption of the tight junction induced by cytokines could occur in vivo, however, there is a possibility that WNV also utilizes a transcellular pathway, which might be promoted by inflammatory cytokines.

The analysis of VLPs with chimeric E proteins showed that $\mathrm{E}$ protein determines the difference in the transport across HUVEC between the 6-LP and Eg strains. Our data also suggest that multiple amino acid residues of $E$ protein are influential. It has been well known that the sequence NYS/T at the residues 154-156 is important for glycosylation associated with the virulence of WNV and that strains possessing proline at the residue 156 lack glycosylation [10,31-33]. The prototype WNV strain B956 has a 4 amino acid deletion in the residues 156-159 resulting in absence of glycosylation [48]. The position of glycosylation seems to be also important, since the WNI25 and WNI-25A strains which have N-glycosylation at the residue 155, do not show neuroinvasive phenotype $[49,50]$. The present study suggests that the combination of Ser 156 and Val 159 is important for transport of VLPs across endothelial cells, which might be associated with the invasion of WNV into the target organs.

The transport of Eg P156 S VLPs was lower than that of WT Eg VLPs in spite of the presence of glycosylation. The residues 156-160 form two turns of $\alpha$-helix, termed $\alpha \mathrm{A}^{\prime}$, although $\mathrm{E}$ proteins of Dengue virus serotype 2 (DENV-2) and Tick-borne encephalitis virus (TBEV) lack the amino acids 157-160 resulting in the absence of this structure[51]. The $\alpha$-helix shifts the glycosylation site about $5 \AA$ to the exterior and lateral surfaces of $E$ protein with respect to those of $\mathrm{E}$ proteins of DENV-2 and TBEV. Davis et al. [52] showed that modulation of N-glycosylation of WNV E protein modified the attachment to DCSIGNR. As well as the existence of proline and the deletion of the amino acids between the residues 156-160, there is a possibility that the combination of amino acid 
residues at 156 and 159 might affect the structure of $\alpha \mathrm{A}^{\prime}$ and position of glycosylation site, resulting in modulation of the binding affinity to a lectin or unknown binding molecules on HUVEC. This, in turn, could be a reason for the unsuccessful transport of Eg P156 S VLPs.

\section{Conclusion}

In this study, we propose a transcellular mechanism by which WNV crosses endothelial cells and enters the target organs. We also suggest that higher transendothelial migration ability could be one of the determinants of the different virulence of the NY and Eg strains, and that this depends on Ser 156 and Val 159 of E protein.

\section{Methods}

\section{Cell culture}

HUVEC were purchased from Lonza Group Ltd. and cultured in EGM-2 Endothelial Cell Growth Medium-2 supplemented with SingleQuots growth factors, cytokines and supplements (Lonza). The cells at passage 5 were used for experiments. Vero cells were cultured in Eagle's minimum essential medium (MEM; Nissui, Tokyo, Japan) supplemented with 5\% fetal bovine serum (FBS; Sigma). Baby hamster kidney (BHK) cells were cultured in MEM supplemented with 10\% FBS. HEK293T cells were cultured in Dulbecco's Modified Eagle Medium (Nissui).

\section{Plasmid Constructs}

The WNV 6-LP and Eg strains were provided by Dr. I. Takashima, Hokkaido University, Japan [15,34]. 6-LP strain was established by plaque purification from WNV NY99-6922 strain, which was isolated from mosquitoes in 1999 [34]. Complement DNA (cDNA) of the structural genes $(\mathrm{C}, \mathrm{prM} / \mathrm{M}$ and $\mathrm{E})$ of the 6-LP and Eg strains were prepared by RT-PCR and subcloned into pCXSN, which was generated from pCMV-Myc (Takara Bio, Shiga, Japan) by replacing the sequence of the Myc tag and multicloning site with restriction enzyme sites of Xho I, Sal I and Not I. The resultant plasmids were designated pCXSN 6-LP CME and pCXSN Eg CME, respectively. For the construction of chimeric VLPs between 6-LP and Eg, a Sma I site was generated by substitution of $t$ to c (in 6$\mathrm{LP}$ ) and a to g (in 6-LP and Eg) at nucleotide positions 460 and 463, respectively, of the prM gene by PCR. The sequence containing the prM gene (nucleotides 461-555) and E gene (nucleotides 1-1500) was digested by Sma I and Not I from pCXSN 6-LP CME or pCXSN Eg CME and inserted into pCXSN Eg CME or PCXSN 6-LP CME. The resultant plasmids were designated pCXSN Eg CM 6-LP E and pCXSN 6-LP CM Eg E, respectively. The constructs for single or double mutant VLPs were generated by PCR with pCXSN 6-LP CME or PCXSN Eg CME.

\section{VLP preparation}

WNV replicon cDNA construct (pWNR NS1-5 EG2 AN), was generously provided by Dr. Peter W. Mason, University of Texas Medical Branch, USA [18]. WNVR NS1-5 EG2 AN encodes the nonstructural proteins (NS1-5) of WNV 3356 strain isolated from American crow in 2000 [53], eGFP, autocatalytic foot-and mouth disease virus $2 \mathrm{~A}$ protease and neomycin phosphotransferase II under the translational control of encephalomyocarditis virus internal ribosomal entry site. One $\mu \mathrm{g}$ of pWNR NS1-5 EG2 AN was linearized with $\mathrm{Xba}$ I and purified with a PCR purification kit (QIAGEN Inc), followed by ethanol precipitation. WNV replicon RNA was produced with in vitro transcription with an mMESSAGE mMASHINE T7 kit (Applied Biosystems) according to the manufacture's instructions. BHK cells $\left(5 \times 10^{6}\right)$ were trypsinized, washed three times with phosphate-buffered saline (PBS) and resuspended in $450 \mu \mathrm{l}$ of PBS. Then, $5 \mu \mathrm{g}$ of replicon RNA was added to the cell suspension and introduced by using a GenePulser II elecroporation apparatus (Bio-Rad Laboratories) at $750 \mathrm{~V}, 25 \mu \mathrm{F}$ with the resistance set to $\infty$. Cells were cultured in $10 \mathrm{~cm}$ dishes with MEM supplemented with 10\% FBS for $24 \mathrm{~h}$. The culture media were replaced with Opti-MEM (Invitrogen) and incubated at $37^{\circ} \mathrm{C}$ for $30 \mathrm{~min}$. The cells were transfected with $12 \mu \mathrm{g}$ of the plasmid encoding the sequence of WNV structural genes by Lipofectamine (Invitrogen). After $48 \mathrm{~h}$, supernatants were collected and cell debris was removed by centrifugation at $1000 \mathrm{~g}$ for $5 \mathrm{~min}$. The supernatants were concentrated with Centriplus (Millipore). For the IFU assay, Vero cells in 24 well plates were infected with serial 10 -fold dilutions of VLP preparations. After a $1 \mathrm{~h}$ incubation at $37^{\circ} \mathrm{C}$, the solutions were removed and replaced with the culture media. After $48 \mathrm{~h}$ p.i., the number of VLPs-infected cells was counted by eGFP signals and the IFU value was calculated.

\section{Monolayer cultures of HUVEC and transport assay of VLPs} HUVEC were seeded in transwell inserts for 24 well plates with polycarbonate membranes having $0.4 \mu \mathrm{m}$ pores (Millipore). The media volumes were $200 \mu \mathrm{l}$ for transwells and $700 \mu \mathrm{l}$ for the lower chambers, respectively. The cells were cultured for 3 days and the integrity of tight junctions was evaluated by measuring TEER using a Millicell ERS (Millipore). The wells showing TEER elevation (more than $66 \Omega \mathrm{cm}^{2}$ ) were used for experiments. For VLPs transport assay, HUVEC were exposed to $4 \times 10^{4} \mathrm{IFU} /$ transwell of VLPs ( 2 m.o.i.). The media in the lower chambers were collected at the indicated time points and subjected to the IFU assay on Vero cells. 


\section{Immunofluorescence of ZO-1}

HUVEC seeded in transwells were exposed with 6-LP VLPs or treated with TNF- $\alpha$. After $24 \mathrm{~h}$, the cells were washed with PBS once and fixed with $4 \%$ paraformaldehyde (PFA) in PBS for $10 \mathrm{~min}$ at room temperature. After washing with PBS three times, the cells were permeabilized with $0.1 \%$ Triton X-100 in PBS and blocked with $2 \%$ bovine serum albumin in PBS (blocking solution) for 15 $\mathrm{min}$ at room temperature. The primary antibody incubation was performed overnight at $4^{\circ} \mathrm{C}$ with rabbit antiserum to human ZO-1 (BD Transduction Laboratories) diluted at 1:1000 in blocking solution. Then the cells were washed with PBS three times, and Alexa 488 conjugated donkey anti-rabbit IgG antibodies (Invitrogen) were added at 1:1000 dilution in blocking solution for a $1 \mathrm{~h}$ incubation at room temperature. After a PBS wash, the membranes were cut from transwell, placed on cover glasses and observed by fluorescent microscopy.

\section{0k Dextran transfer assay}

Fluorescein (FITC)-labeled 70k Dx (Invitrogen) was added into HUVEC with 6-LP VLPs, TNF- $\alpha$ (positive control) or media (negative control). After $24 \mathrm{~h}$ incubation at $37^{\circ} \mathrm{C}, 100 \mu \mathrm{l}$ of medium was collected from each well and transferred into a 96-well plate. The FITC signal was read by a fluorescent plate reader, Mithras LB940 (Berthold). The relative transfer of $70 \mathrm{k}$ Dx was calculated by dividing the FITC signal of samples incubated with 6LP VLPs or TNF- $\alpha$ by the mean of the signal of the negative control. The relative transfer of 70k Dx in the negative control was defined as 1 .

\section{Effect of endocytosis inhibitors on the transport of 6-LP VLPs}

For stock solutions, chlorpromazine (Sigma) and filipin III (Sigma) were dissolved in dimethyl sulfoxide (DMSO) at 5 and $1 \mathrm{mg} / \mathrm{ml}$, respectively. HUVEC in transwells were preincubated with the inhibitor at the indicated concentration for $30 \mathrm{~min}$, and exposed to 6-LP VLPs for $24 \mathrm{~h}$. For the control, DMSO was added in the media at concentration of $0.1 \%$. The evaluation of the transported VLPs was performed as described above. The integrity of monolayer of HUVEC was confirmed by the 70k Dx transfer assay described above.

\section{Western blotting for E protein}

Wild type or mutant VLPs were produced with 293T cells as described above. Supernatants from cell cultures were subjected to sodium dodecyl sulfate-polyacrylamide gel electrophoresis and Western blotting with a mouse monoclonal antibody to WNV E protein clone $3.91 \mathrm{D}$ (Millipore) for the primary antibody and horseradish peroxidase (HRP)-conjugated goat antibodies to mouse immunoglobulin (1:5,000 dilution; Biosource). The immunocomplex was visualized with Immobilon ${ }^{\text {ma }}$ West- ern chemiluminescent HRP substrate (Millipore) and LAS-1000 mini (FIJIFILM, Tokyo, Japan).

\section{Statistical analysis}

Quantitative data are expressed as means \pm standard deviation (SD) and were compared with Student's $t$ test.

\section{Authors' contributions}

Conception and design: $\mathrm{RH}$; Acquisition of data: $\mathrm{RH}, \mathrm{TS}, \mathrm{SY}$; Analysis and Interpretation of data: $\mathrm{RH}, \mathrm{TS}, \mathrm{YM}, \mathrm{MI}, \mathrm{AM}, \mathrm{MH}, \mathrm{HS}$, TK; Drafting the paper: $\mathrm{RH}$

All authors read and approved the final manuscript.

\section{Acknowledgements}

The authors gratefully acknowledge the invaluable suggestions by Dr. B. Caughey and Dr. C. D. Orrú, Rocky Mountain Laboratories, NIAID, NIH. The authors are grateful to Dr. P. W. Mason, University of Texas Medical Branch for WNV replicon cDNA construct. The authors acknowledge Dr. I. Takashima, Hokkaido University for providing WNV NY99 6-LP and Eg strains. The authors thank Ms. M. Sasada for technical assistance. This work was supported in part by Grant-in-Aids for young scientist B (R. H.), Scientific Research C (T. K.) and the Program of Founding Research Centers for Emerging and Reemerging Infectious Diseases (R. H., T. K. and H. S.) from the Ministry of Education, Culture, Sports, Science and Technology, Japan.

\section{Author Details}

1Department of Molecular Pathobiology, Hokkaido University Research Center for Zoonosis Control, Kita 20, Nishi 10, Kita-ku, Sapporo 001-0020, Japan, 2Laboratory of Veterinary Hygiene, Graduate School of Veterinary Medicine, Hokkaido University, Kita 18, Nishi 9, Kita-ku, Sapporo 060-0818, Japan, ${ }^{3}$ Department of Global Epidemiology, Hokkaido University Research Center for Zoonosis Control, Kita 20, Nishi 10, Kita-ku, Sapporo 001-0020, Japan and ${ }^{4}$ Global COE program, Hokkaido University, Japan

Received: 13 January 2010 Accepted: 8 June 2010

Published: 8 June 2010

\section{References}

1. Cernescu C, Ruta SM, Tardei G, Grancea C, Moldoveanu L, Spulbar E, Tsai T: A high number of severe neurologic clinical forms during an epidemic of West Nile virus infection. Rom J Virol 1997, 48(1-4):13-25.

2. Jamgaonkar AV, Yergolkar PN, Geevarghese G, Joshi GD, Joshi MV, Mishra AC: Serological evidence for Japanese encephalitis virus and West Nile virus infections in water frequenting and terrestrial wild birds in Kolar District, Karnataka State, India. A retrospective study. Acta Virol 2003, 47(3):185-188.

3. Malkinson M, Banet C, Weisman Y, Pokamunski S, King R, Drouet MT, Deubel V: Introduction of West Nile virus in the Middle East by migrating white storks. Emerg Infect Dis 2002, 8(4):392-397.

4. Murgue B, Zeller H, Deubel V: The ecology and epidemiology of West Nile virus in Africa, Europe and Asia. Curr Top Microbiol Immunol 2002, 267:195-221.

5. Asnis DS, Conetta R, Teixeira AA, Waldman G, Sampson BA: The West Nile Virus outbreak of 1999 in New York: the Flushing Hospital experience. Clin Infect Dis 2000, 30(3):413-418.

6. Nash D, Mostashari F, Fine A, Miller J, O'Leary D, Murray K, Huang A, Rosenberg A, Greenberg A, Sherman M, et al:: The outbreak of West Nile virus infection in the New York City area in 1999. N Engl J Med 2001, 344(24):1807-1814.

7. Trock SC, Meade BJ, Glaser AL, Ostlund EN, Lanciotti RS, Cropp BC, Kulasekera V, Kramer LD, Komar N: West Nile virus outbreak among horses in New York State, 1999 and 2000. Emerg Infect Dis 2001, 7(4):745-747.

8. Artsob H, Gubler DJ, Enria DA, Morales MA, Pupo M, Bunning ML, Dudley JP: West Nile Virus in the New World: Trends in the Spread and Proliferation of West Nile Virus in the Western Hemisphere. Zoonoses Public Health 2009.

9. Lindsey NP, Kuhn S, Campbell GL, Hayes EB: West Nile virus neuroinvasive disease incidence in the United States, 2002-2006. Vector Borne Zoonotic Dis 2008, 8(1):35-39. 
10. Schneider BS, Soong L, Girard YA, Campbell G, Mason P, Higgs S: Potentiation of West Nile encephalitis by mosquito feeding. Viral Immunol 2006, 19(1):74-82.

11. Sampson BA, Ambrosi C, Charlot A, Reiber K, Veress JF, Armbrustmacher V: The pathology of human West Nile Virus infection. Hum Pathol 2000, 31(5):527-531.

12. Khouzam RN: Significant cardiomyopathy secondary to West Nile virus infection. South Med J 2009, 102(5):527-528.

13. Gupta M, Ghaffari M, Freire AX: Rhabdomyolysis in a patient with West Nile encephalitis and flaccid paralysis. Tenn Med 2008, 101(4):45-47.

14. Armah HB, Wang G, Omalu BI, Tesh RB, Gyure KA, Chute DJ, Smith RD, Dulai P, Vinters HV, Kleinschmidt-DeMasters BK, et al:: Systemic distribution of West Nile virus infection: postmortem immunohistochemical study of six cases. Brain Pathol 2007 17(4):354-362

15. Shirato K, Kimura T, Mizutani T, Kariwa H, Takashima I: Different chemokine expression in lethal and non-lethal murine West Nile virus infection. J Med Virol 2004, 74(3):507-513.

16. Verma S, Lo Y, Chapagain M, Lum S, Kumar M, Gurjav U, Luo H, Nakatsuka A, Nerurkar VR: West Nile virus infection modulates human brain microvascular endothelial cells tight junction proteins and cell adhesion molecules: Transmigration across the in vitro blood-brain barrier. Virology 2009, 385(2):425-433

17. Paddock CD, Nicholson WL, Bhatnagar J, Goldsmith CS, Greer PW, Hayes EB, Risko JA, Henderson C, Blackmore CG, Lanciotti RS: Fatal hemorrhagic fever caused by West Nile virus in the United States. Clin Infect Dis 2006, 42(11):1527-1535.

18. Scholle F, Girard YA, Zhao Q, Higgs S, Mason PW: trans-Packaged West Nile virus-like particles: infectious properties in vitro and in infected mosquito vectors. J Virol 2004, 78(21):11605-11614.

19. McKenzie JA, Ridley AJ: Roles of Rho/ROCK and MLCK in TNF-alphainduced changes in endothelial morphology and permeability. J Cell Physiol 2007, 213(1):221-228.

20. Subtil A, Hemar A, Dautry-Varsat A: Rapid endocytosis of interleukin 2 receptors when clathrin-coated pit endocytosis is inhibited. J Cell Sci 1994, 107(Pt 12):3461-3468.

21. Orlandi PA, Fishman PH: Filipin-dependent inhibition of cholera toxin: evidence for toxin internalization and activation through caveolae-like domains. J Cell Biol 1998, 141(4):905-915.

22. Beasley DW, Barrett AD: Identification of neutralizing epitopes within structural domain III of the West Nile virus envelope protein. J Virol 2002, 76(24):13097-13100.

23. Chu JH, Chiang CC, Ng ML: Immunization of flavivirus West Nile recombinant envelope domain III protein induced specific immune response and protection against West Nile virus infection. J Immunol 2007, 178(5):2699-2705

24. Chu JJ, Leong PW, Ng ML: Characterization of plasma membraneassociated proteins from Aedes albopictus mosquito $(\mathrm{C} 6 / 36)$ cells that mediate West Nile virus binding and infection. Virology 2005, 339(2):249-260

25. Chu JJ, Ng ML: Interaction of West Nile virus with alpha v beta 3 integrin mediates virus entry into cells. J Bio/ Chem 2004, 279(52):54533-54541.

26. Chu JJ, Rajamanonmani R, Li J, Bhuvanakantham R, Lescar J, Ng ML: Inhibition of West Nile virus entry by using a recombinant domain III from the envelope glycoprotein. J Gen Virol 2005, 86(Pt 2):405-412.

27. Lee JW, Chu JJ, Ng ML: Quantifying the specific binding between West Nile virus envelope domain III protein and the cellular receptor alphaVbeta3 integrin. J Bio/ Chem 2006, 281(3):1352-1360.

28. Li L, Barrett AD, Beasley DW: Differential expression of domain III neutralizing epitopes on the envelope proteins of West Nile virus strains. Virology 2005, 335(1):99-105.

29. Chu JJ, Ng ML: Infectious entry of West Nile virus occurs through a clathrin-mediated endocytic pathway. J Virol 2004, 78(19):10543-10555.

30. Medigeshi GR, Hirsch AJ, Streblow DN, Nikolich-Zugich J, Nelson JA: West Nile virus entry requires cholesterol-rich membrane microdomains and is independent of alphavbeta3 integrin. J Viro/ 2008, 82(11):5212-5219.

31. Beasley DW, Davis CT, Estrada-Franco J, Navarro-Lopez R, CampomanesCortes A, Tesh RB, Weaver SC, Barrett AD: Genome sequence and attenuating mutations in West Nile virus isolate from Mexico. Emerg Infect Dis 2004, 10(12):2221-2224.
32. Beasley DW, Li L, Suderman MT, Barrett AD: Mouse neuroinvasive phenotype of West Nile virus strains varies depending upon virus genotype. Virology 2002, 296(1):17-23.

33. Beasley DW, Whiteman MC, Zhang S, Huang CY, Schneider BS, Smith DR Gromowski GD, Higgs S, Kinney RM, Barrett AD: Envelope protein glycosylation status influences mouse neuroinvasion phenotype of genetic lineage 1 West Nile virus strains. J Virol 2005, 79(13):8339-8347.

34. Shirato K, Miyoshi H, Goto A, Ako Y, Ueki T, Kariwa H, Takashima I: Viral envelope protein glycosylation is a molecular determinant of the neuroinvasiveness of the New York strain of West Nile virus. J Gen Virol 2004, 85(Pt 12):3637-3645

35. Bazzoni G, Dejana E: Endothelial cell-to-cell junctions: molecular organization and role in vascular homeostasis. Physiol Rev 2004 84(3):869-901

36. Huang $\mathrm{SH}$, Jong $\mathrm{AY}$ : Cellular mechanisms of microbial proteins contributing to invasion of the blood-brain barrier. Cell Microbiol 2001, 3(5):277-287.

37. Defazio G, Gelati M, Corsini E, Nico B, Dufour A, Massa G, Salmaggi A: In vitro modulation of adhesion molecules, adhesion phenomena, and fluid phase endocytosis on human umbilical vein endothelial cells and brain-derived microvascular endothelium by IFN-beta 1a. J Interferon Cytokine Res 2001, 21(5):267-272.

38. Kallmann BA, Wagner S, Hummel V, Buttmann M, Bayas A, Tonn JC, Rieckmann $P$ : Characteristic gene expression profile of primary human cerebral endothelial cells. FASEB J 2002, 16(6):589-591.

39. Stins MF, Gilles F, Kim KS: Selective expression of adhesion molecules on human brain microvascular endothelial cells. J Neuroimmunol 1997 76(1-2):81-90

40. Man S, Ubogu EE, Williams KA, Tucky B, Callahan MK, Ransohoff RM: Human brain microvascular endothelial cells and umbilical vein endothelial cells differentially facilitate leukocyte recruitment and utilize chemokines for T cell migration. Clin Dev Immunol 2008, 2008:384982

41. Shukaliak JA, Dorovini-Zis K: Expression of the beta-chemokines RANTES and MIP-1 beta by human brain microvessel endothelial cells in primary culture. J Neuropathol Exp Neurol 2000, 59(5):339-352.

42. Arjona A, Foellmer HG, Town T, Leng L, McDonald C, Wang T, Wong SJ, Montgomery RR, Fikrig E, Bucala R: Abrogation of macrophage migration inhibitory factor decreases West Nile virus lethality by limiting viral neuroinvasion. J Clin Invest 2007, 117(10):3059-3066.

43. Garcia-Tapia D, Hassett DE, Mitchell WJ, Johnson GC, Kleiboeker SB: West Nile virus encephalitis: sequential histopathological and immunological events in a murine model of infection. J Neurovirol 2007, 13(2):130-138

44. Shrestha B, Ng T, Chu HJ, Noll M, Diamond MS: The relative contribution of antibody and CD8+ T cells to vaccine immunity against West Nile encephalitis virus. Vaccine 2008, 26(16):2020-2033.

45. Wang T, Town T, Alexopoulou L, Anderson JF, Fikrig E, Flavell RA: Toll-like receptor 3 mediates West Nile virus entry into the brain causing lethal encephalitis. Nat Med 2004, 10(12):1366-1373.

46. Fiala M, Looney DJ, Stins M, Way DD, Zhang L, Gan X, Chiappelli F, Schweitzer ES, Shapshak P, Weinand M, et al:: TNF-alpha opens a paracellular route for HIV-1 invasion across the blood-brain barrier. Mol Med 1997, 3(8):553-564

47. Miller F, Fenart L, Landry V, Coisne C, Cecchelli R, Dehouck MP, BueeScherrer $V$ : The MAP kinase pathway mediates transcytosis induced by TNF-alpha in an in vitro blood-brain barrier model. Eur J Neurosci 2005, 22(4):835-844

48. Yamshchikov G, Borisevich V, Seregin A, Chaporgina E, Mishina M, Michin V, Kwok CW, Yamshchikov V: An attenuated West Nile prototype virus is highly immunogenic and protects against the deadly NY99 strain: a candidate for live WN vaccine development. Virology 2004, 330(1):304-312

49. Chambers TJ, Halevy N, Nestorowicz A, Rice CM, Lustig S: West Nile virus envelope proteins: nucleotide sequence analysis of strains differing in mouse neuroinvasiveness. J Gen Virol 1998, 79(10):2375-2380.

50. Halevy M, Akov Y, Ben-Nathan D, Kobiler D, Lachmi B, Lustig S: Loss of active neuroinvasiveness in attenuated strains of West Nile virus: pathogenicity in immunocompetent and SCID mice. Arch Virol 1994, 137(34):355-70 
51. Nybakken GE, Nelson CA, Chen BR, Diamond MS, Fremont DH: Crystal structure of the West Nile virus envelope glycoprotein. J Virol 2006, 80(23):11467-11474

52. Davis CW, Nguyen HY, Hanna SL, Sanchez MD, Doms RW, Pierson TC: West Nile virus discriminates between DC-SIGN and DC-SIGNR for cellular attachment and infection. J Virol 2006, 80(3):1290-1301.

53. Shi PY, Tilgner M, Lo MK: Construction and characterization of subgenomic replicons of New York strain of West Nile virus. Virology 2002, 296(2):219-233.

doi: 10.1186/1471-2180-10-165

Cite this article as: Hasebe et al., Transcellular transport of West Nile viruslike particles across human endothelial cells depends on residues 156 and 159 of envelope protein BMC Microbiology 2010, 10:165

Submit your next manuscript to BioMed Central and take full advantage of:

- Convenient online submission

- Thorough peer review

- No space constraints or color figure charges

- Immediate publication on acceptance

- Inclusion in PubMed, CAS, Scopus and Google Scholar

- Research which is freely available for redistribution

Submit your manuscript at www.biomedcentral.com/submit 